Research article

\title{
On the activity loss of hydrolases in organic solvents: II. a mechanistic study of subtilisin Carlsberg Betzaida Castillo', Vibha Bansal2 ${ }^{2}$, Ashok Ganesan ${ }^{3}$, Peter Halling3, Francesco Secundo ${ }^{4}$, Amaris Ferrer ${ }^{2}$, Kai Griebenow ${ }^{1}$ and Gabriel Barletta*2
}

Address: ${ }^{1}$ Department of Chemistry, University of Puerto Rico, Rio Piedras Campus, P.O Box 23346, San Juan, 00931-3346, Puerto Rico, ${ }^{2}$ Department of Chemistry, University of Puerto Rico at Humacao, CUH Station, Humacao, 00791, Puerto Rico, ${ }^{3}$ WestCHEM, Department of Pure \& Applied Chemistry, University of Strathclyde, Glasgow G1 1XL, UK and ${ }^{4}$ Istituto di Chimica del Riconoscimento Molecolare, CNR, Via Mario Bianco 9, 20131 Milano, Italy

Email: Betzaida Castillo - betzaida.castillo@yahoo.com;Vibha Bansal - vibha_bansal2000@yahoo.co.uk: Ashok Ganesan - ashok.ganesan@strath.ac.uk; Peter Halling - p.j.halling@strath.ac.uk; Francesco Secundo - secundo@mx.isti.cnr.it; Amaris Ferrer - a_ferrer@webmail.uprh.edu; Kai Griebenow - griebeno@adam.uprr.pr; Gabriel Barletta* - barletta@quimica.uprh.edu

* Corresponding author

Published: 22 December 2006

BMC Biotechnology 2006, 6:5I doi:|0.||86/|472-6750-6-5I
Received: 10 August 2006

Accepted: 22 December 2006

This article is available from: http://www.biomedcentral.com/l472-6750/6/5 I

(C) 2006 Castillo et al; licensee BioMed Central Ltd.

This is an Open Access article distributed under the terms of the Creative Commons Attribution License (http://creativecommons.org/licenses/by/2.0), which permits unrestricted use, distribution, and reproduction in any medium, provided the original work is properly cited.

\begin{abstract}
Background: Enzymes have been extensively used in organic solvents to catalyze a variety of transformations of biological and industrial significance. It has been generally accepted that in dry aprotic organic solvents, enzymes are kinetically trapped in their conformation due to the high-energy barrier needed for them to unfold, suggesting that in such media they should remain catalytically active for long periods. However, recent studies on a variety of enzymes demonstrate that their initial high activity is severely reduced after exposure to organic solvents for several hours. It was speculated that this could be due to structural perturbations, changes of the enzyme's $\mathrm{pH}$ memory, enzyme aggregation, or dehydration due to water removal by the solvents. Herein, we systematically study the possible causes for this undesirable activity loss in I,4-dioxane.

Results: As model enzyme, we employed the protease subtilisin Carlsberg, prepared by lyophilization and colyophilization with the additive methyl- $\beta$-cyclodextrin $(M \beta C D)$. Our results exclude a mechanism involving a change in ionization state of the enzyme, since the enzyme activity shows a similar $\mathrm{pH}$ dependence before and after incubation for 5 days in I,4-dioxane. No apparent secondary or tertiary structural perturbations resulting from prolonged exposure in this solvent were detected. Furthermore, active site titration revealed that the number of active sites remained constant during incubation. Additionally, the hydration level of the enzyme does not seem to affect its stability. Electron paramagnetic resonance spectroscopy studies revealed no substantial increase in the rotational freedom of a paramagnetic nitroxide inhibitor bound to the active site (a spin-label) during incubation in neat I,4-dioxane, when the water activity was kept constant using $\mathrm{BaBr}_{2}$ hydrated salts. Incubation was also accompanied by a substantial decrease in $\mathrm{V}_{\max } / \mathrm{K}_{\mathrm{M}}$.
\end{abstract}

Conclusion: These results exclude some of the most obvious causes for the observed low enzyme storage stability in I,4-dioxane, mainly structural, dynamics and ionization state changes. The most likely explanation is possible rearrangement of water molecules within the enzyme that could affect its dielectric environment. However, other mechanisms, such as small distortions around the active site or rearrangement of counter ions, cannot be excluded at this time. 


\section{Background}

Enzymes have been successfully employed to catalyze a number of transformations and chiral resolutions of biological and industrial importance in organic solvents [110]] It is well documented that enzyme catalysis in these non-natural media offers some advantages over that in natural-aqueous environment, such as: prevention of autolysis (in case of proteases) and increased thermostability $[11,12]$. In fact, it has been shown that enzymes can perform catalysis in organic solvents at temperatures far above those temperatures that denature enzymes in aqueous systems [8]. Despite this, enzyme inactivation in organic solvents has been reported, and studies have addressed this issue. For example, Fagain et al. (2003) have recently reviewed bioreactor stability, shelf life and operational stability of a variety of enzymes suspended in neat organic solvents and aqueous-organic solvent mixtures [13].

We have previously reported that the activity of the serine protease subtilisin Carlsberg is significantly reduced upon storage in several organic solvents, irrespective of its preparation, hydration, hydrophobicity of the solvent, the reaction temperature and of the substrates used [14]. A subsequent study using various lipases, an esterase, and $\alpha$ chymotrypsin showed that for these enzymes most of their initial high activity also plunges upon exposure to organic solvents [15]. It was found that some additives and modes of enzyme preparation (such as chemical modification with polyethylene glycol) were able to reduce activity loss of the enzymes in various organic solvents. The other variables studied (enzyme hydration, the reaction temperature, the organic solvent and the enzymes themselves) were not found to affect the rapid loss of activity observed. Furthermore, experiments using structurally defined cross-linked enzyme crystals (CLECs) $[11,16]$ suggested that the mechanism of inactivation might not involve large structural changes of the enzyme catalyst. The activity loss was reversible upon re-lyophilizing the enzyme from an aqueous buffer, indicating that inactivation did not involve autolysis or irreversible denaturation of the enzyme [14].

Those findings outline a clear drawback in the use of biocatalysts for applications that require prolonged exposure to organic solvents, and showed the need for understanding the mechanism of enzyme inactivation during storage in these media. Herein we study this detrimental effect in detail using two different preparations of the model enzyme subtilisin Carlsberg.

\section{Results}

The results previously reported from this and other laboratories demonstrated that most enzymes lose their initial high activity exponentially during the first hours of incu- bation in a variety of organic solvents until a constant activity value is reached. So far, all of the enzymes studied show some residual activity after a long incubation period (usually from 4 to 7 days), which appears to persist indefinitely $[14,15,17]$. However, no mechanistic explanation for this phenomenon has been provided so far. Herein we examine the structure, the flexibility, the number of active sites remaining, the powder morphology, and the $\mathrm{pH}$ profile of subtilisin Carlsberg as some of the possible causes that could contribute to the observed decrease in enzyme activity after prolonged exposure to organic media. We had previously demonstrated that subtilisin Carlsberg instability was independent of: (a) the mode of enzyme preparation (lyophilized, co-lyophilized and CLECs - all showed a similar stability profile); (b) the physicochemical properties of the solvents used; and (c) the substrates [14]. Subsequent studies involving different preparations of $\alpha$-chymotrypsin, pig-liver esterase and several lipases showed that this was not unique to subtilisin, but rather a common effect shared by several enzymes [15].

First, we decided to study the enzyme-powder morphology after suspension in 1,4-dioxane since it has been suggested that incubation could result in larger and more compact aggregates, which could reduce the enzyme activity.

\section{Enzyme morphology}

Since most of the enzyme preparations studied were suspensions, and therefore the substrates would have to diffuse through solution and through the pores of solid particles to reach their corresponding active sites, it is conceivable that particle aggregation or morphology changes (such as shrinking or powder deformation) could have an adverse effect on the substrate's diffusion to the enzyme's active site. Scanning Electron Microscopy (SEM) of the suspended particles of the co-lyophilized enzyme in 1,4dioxane showed that no apparent morphological changes or aggregation occurred during incubation (Figure 1). The typical flaky suspended particles remained nearly of the same size, shape, and morphology, suggesting that this is probably not the cause for the activity drop. In agreement with these results, a soluble preparation of the same enzyme, for which its activity should not be compromised by aggregation or morphological changes, also showed a decrease in activity during incubation, similar to what was observed with their suspended counterparts [15]. From these results we can rule out substrate diffusion limitations as a possible cause for the observed decrease in enzyme activity.

\section{Active-site titration and Michaelis constant}

Next, as a likely cause for this effect, we decided to determine if the fraction of active enzyme molecules decreases during incubation. Active-site titration, employing the 
A

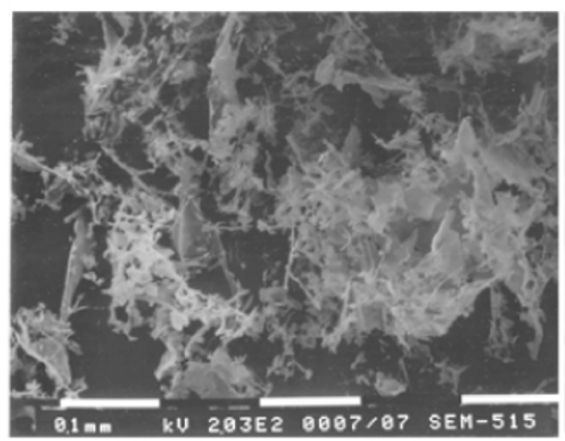

B

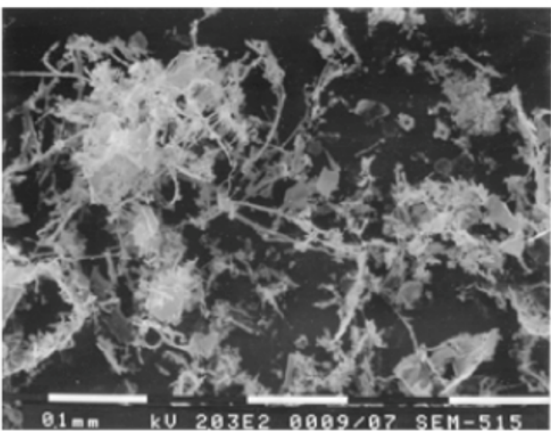

$\mathrm{C}$

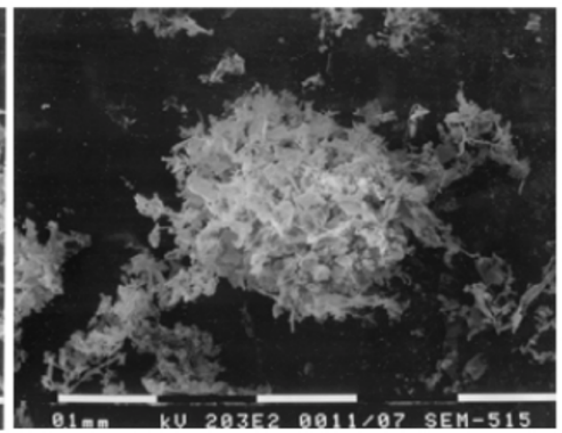

\section{Figure I}

Scanning electron microscopy (SEM) of co-lyophilized subtilisin C. in I,4-dioxane. Incubation times in I,4-dioxane: (A) I0 minutes; (B) 3 hrs; (C) 4 days. The color segments of the scale bars (shown on the figures) are of $0.1 \mathrm{~mm}$.

method described by Wangikar et al., [18] of the lyophilized powder before and after incubation in 1,4-dioxane, at $45^{\circ} \mathrm{C}$, showed no change in the number of competent active-sites: $17 \pm 2 \%$ before incubation and $20 \pm 2 \%$ after incubation. The apparent $\mathrm{V}_{\max }$ calculated for the colyophilized preparation in 1,4-dioxane was substantially reduced after a 4-day incubation period. The apparent Michaelis constant $\left(\mathrm{K}_{\mathrm{M}}\right)$ calculated for the co-lyophilized preparation increased substantially after the incubation period (Table 1 ). Furthermore, the $\mathrm{V}_{\max } / \mathrm{K}_{\mathrm{M}}$ showed a substantial decrease after incubation (Table 1). For Ping-Pong kinetics, a true value of $\mathrm{V}_{\max } / \mathrm{K}_{\mathrm{M}}$ is obtained even when only one substrate concentration is varied (as in our experiments), so it seems that the observed drop in activity is due to a deficiency in the catalytic efficiency of the enzyme. The increase in the $K_{M}$ value could indicate subtle structural changes of surface amino groups involved in the substrate binding process. Such subtle (reversible) structural changes of active site residues could also explain decreased catalytic efficiency of the catalyst.

\section{Structural analysis}

It is well documented that the dehydration step, required before introducing an enzyme to the organic medium (and usually achieved by lyophilization), induces structural perturbation in the enzyme's secondary structure $[12,19]$. It has also been shown that subsequent introduction to organic media (aprotic organic solvents) does not induce additional structural perturbations in an enzyme (since an enzyme suspended in such medium would not be able to rearrange its hydrogen bonds, and it will therefore be structurally stable) $[20,21]$. However, it is possible that structural perturbations or partial denaturation resulting from water removal, solvent insertion, or protein relaxation could take place over a prolonged exposure to neat organic solvents, and this might explain our observed-reduced enzyme activity after incubation. Secondary structure analysis of the lyophilized and the colyophilized powders before and after incubation in 1,4dioxane by Fourier Transform Infrared Spectroscopy (FTIR) revealed no significant secondary structural changes. The SCC of the lyophilized powder before incubation was found to be 0.7105 (determined with respect to the native enzyme) and 0.6717 after incubation (yielding a negligible difference of 0.0388). Similarly, the SCC of the co-lyophilized enzyme before and after incubation were nearly identical (0.7539 and 0.7235, (Figure 2$)$. Furthermore, the inverted second derivative absorbance spectra in dry state and in a different solvent, THF, are also nearly identical. These results suggest that no secondary changes or extensive autolysis occurs during incubation in these solvent, in agreement with our active-site titration results and previous findings $[14,15]$.

Table I: Castillo et al., Table I Kinetic parameters of subtilisin C. co-lyophilized with methyl- $\beta$-cyclodextrin

\begin{tabular}{ccc}
\hline & \multicolumn{3}{c}{ I,4-Dioxane } \\
\cline { 3 - 4 } & Day 0 & Day 4 \\
\cline { 3 - 4 } $\mathrm{V}_{\max }{ }^{\mathrm{a}}$ & $102 \pm 3$ & $16 \pm 2$ \\
$\mathrm{~K}_{\mathrm{M}}^{\mathrm{b}}$ & $130 \pm 10$ & $319 \pm 48$ \\
$\mathrm{~V}_{\max } / \mathrm{K}_{M}$ & 0.78 & 0.050 \\
\hline
\end{tabular}

amMmin-1, bmM, both values were obtained plotting the initial velocity $(\mathrm{V})$ vs $(\mathrm{V} /[\mathrm{S}])$. Model reaction: transesterification between phenyl alcohol and vinyl butyrate at $45^{\circ} \mathrm{C}$. 


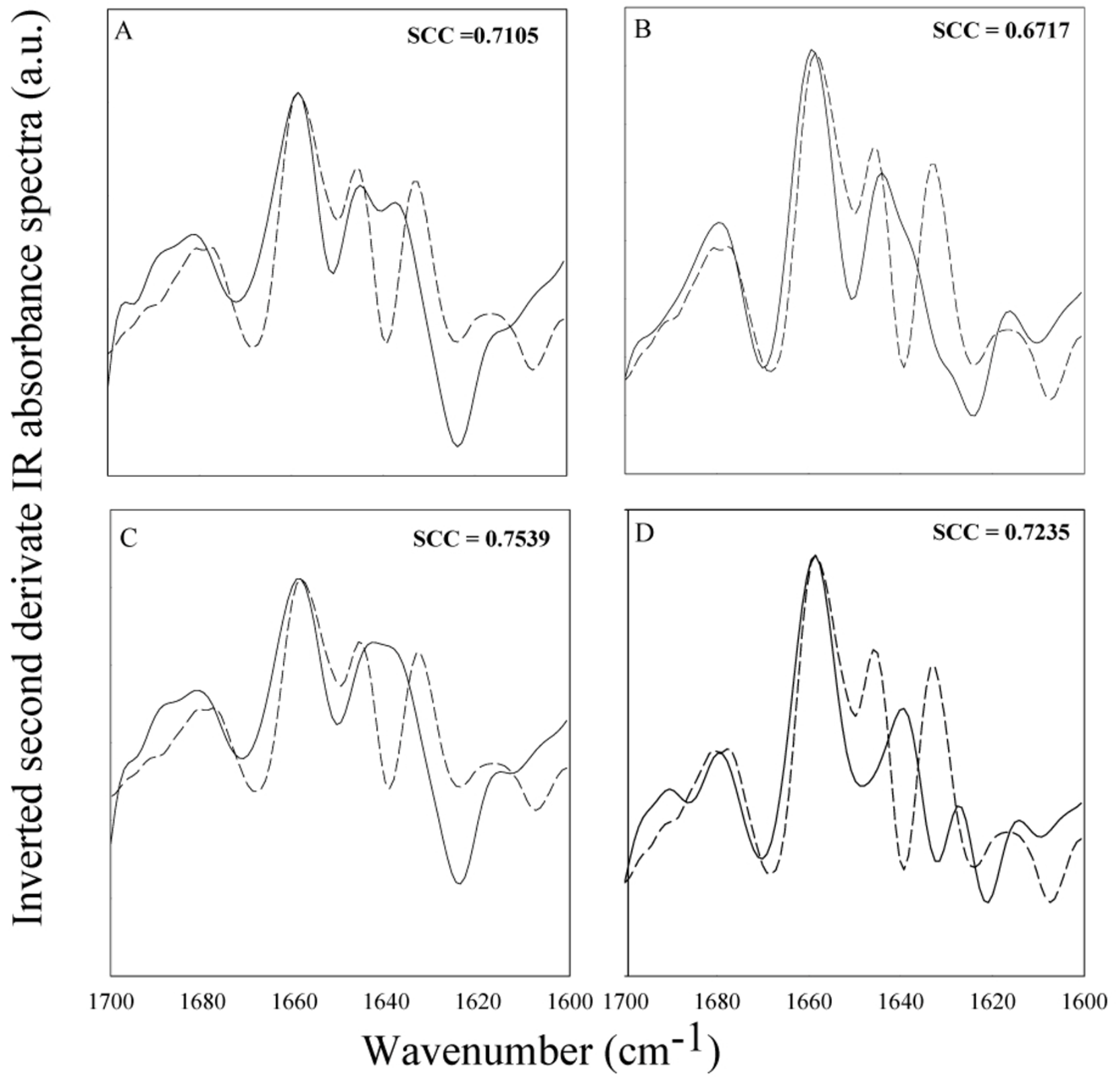

Figure 2

Inverted second derivative absorbance spectra of subtilisin: in aqueous medium (dashed line) and after suspension in I,4-dioxane (solid line) at different times of incubation. Lyophilized powder before incubation (A), and after incubation for 4 days (B). Co-lyophilized enzyme before (C), and after incubation for 4 days (D). 
To further probe changes in structure, including the tertiary structure, we used circular dichroism spectroscopy (CD). Spectra were recorded for both the lyophilized and the co-lyophilized powders before and after incubation in 1,4-dioxane for 4 days (Figure 3). The near UV CD of neither enzyme preparation was influenced by incubation, illustrating that the enzyme tertiary structure in both preparations remains unaffected. The far UV CD of the colyophilized enzyme is also unaffected, but the lyophilized powder shows a reduction in ellipticity, which was reproducible. It is unusual for a protein to show spectral changes in the far UV but not in the near UV regions, because this implies a change in secondary structure without change in tertiary structure. However, far UV CD of particulate samples is significantly affected by absorption flattening, for which a semi-empirical correction may be made [27]. The correction involves one adjustable parameter per sample, and it is possible to choose values such that the spectra for the fresh and incubated samples are the same within experimental error. However, this must remain tentative, because here we have no independent method to estimate the correction parameters. A change in absorption flattening would also be most likely to result from a change in particle structure, and none was observed in the SEM imaging studies. The spectra of the colyophilized preparation shows higher ellipticity than the lyophilized powder (Figure 3). This is most likely due to a difference in absorption flattening because the particles are different in nature. The co-lyophilized preparation was observed to disperse in dioxane better than the lyophilized powder did. It is also possible that association with chiral $\beta$-methyl cyclodextrin (the additive) induces increased $\mathrm{CD}$ from the protein peptide bonds.

\section{Enzyme pH profile}

Hydrolases have been shown to exhibit optimum catalytic activity at a specific $\mathrm{pH}$, where the enzyme-catalytic triad residues acquire the most favorable ionization state for catalysis. This "tuning up" of an enzyme's pH is a particularly important step in non aqueous enzymology, and it is often accomplished while the enzyme is dissolved in a buffer prior to dehydration (usually by lyophilization) before suspension in the organic solvent of choice [9]. It is also well documented that, once in an organic solvent, most enzymes "remember" their ionization state from the aqueous solution they were dissolved in prior to dehydration [8]. This is often referred to as "the enzyme's pH memory" [8]. We decided to verify if the decrease in activity observed after an incubation period could be related to the loss or to a "shift" of this pH memory optimum (subtilisin's optimum pH in aqueous buffer is 7.8). Both preparations showed a lyophilization $\mathrm{pH}$ optimum of 7.8, which persists after a five-day incubation period. The activity vs pH profiles (Figures 4 and 5, presented as log initial activity vs $\mathrm{pH}$ plots to express the possible linear correlation of the data) show that the effect of lyophilization $\mathrm{pH}$ is still strong after incubation (which is more evident for the co-lyophilized enzyme, Figure 4), suggesting that the activity loss is not due to a shift or loss of the enzyme's pH memory. The enantioselectivities of both preparations obtained at different $\mathrm{pH}$ and incubation times remained essentially constant (within a 15\% error) over a wide $\mathrm{pH}$ range (from $\mathrm{pH} 6.5$ to 8.5), but it decreased slightly at the extreme $\mathrm{pH}$ 's.

\section{Active site spin labeling}

It is believed that enzyme flexibility and dynamics are directly related to its activity (and enantioselectivity) in a given solvent. Therefore, it is possible that the reduced activity observed after incubation is due to changes of the enzyme's dynamics, occurring either by solvent insertion into the enzyme, water removal or over relaxation of the active-site. Site directed spin labeling (SDSL) is emerging as a new tool for determination of structure and conformational dynamics of proteins [22]. The basic strategy of SDSL is to introduce a paramagnetic nitroxide side chain at a specific site in a protein sequence and to analyze the EPR spectrum of the spin labeled protein in terms of environmental parameters that characterize the site in protein fold. Changes of macromolecular configuration influencing the surroundings of a covalently attached spin label are reflected in the label's degree of immobilization, which can be given a quantitative expression in terms of its rotational correlation time $(\tau)$ [23]. When the label is freely tumbling in solution, its spectrum consists of three narrow lines of equal intensity. As the rate of tumbling slows from that in free solution, the three lines broaden unequally and the spectrum becomes asymmetric. From such a spectrum the rotational correlation time $(\tau)$ can be calculated. Tau is related to the time required for the label to rotate an average of $40^{\circ}$ and is a measure of the rotational freedom of the label's "side chain" (this is defined as the entire label moiety bound to the enzyme group). A large value of $\tau$ indicates slow rotation, while rapid tumbling is associated with low values of $\tau$. For fast isotropic motions of spin labels $\left(\tau_{\mathrm{c}} \sim 10^{-11}\right.$ to $\left.10^{-9} \mathrm{~s}\right)$ the apparent rotational correlation time of spin labels can be obtained from line width and the line amplitude measured from the EPR spectra (Figure 6), using Equation 1 [24].

Equation 1: $\tau(\mathrm{s})=6.5 \times 10^{-10} \Delta \mathrm{H}_{0}\left[\left(\mathrm{~h}_{0} / \mathrm{h}_{-1}\right)^{1 / 2-1}\right]$

For slow molecular motions $\left(\tau>3 \times 10^{-9} \mathrm{~s}\right)$, the line positions depend on the rate as well as the amplitude of motion. Hence, the parameter $\Delta \mathbf{H}_{0}$ can be used as a convenient empirical measure of dynamics, including both amplitude and rate of motion (a decrease in $\Delta \mathbf{H}_{0}$ indicates increased degree of freedom). In addition, the parameters $\mathbf{h}_{\mathbf{i}}$ and $\mathbf{h}_{\mathbf{a}}$ (spectra shown on (Figure 7 ) can also be used to determine the freedom of rotation of the spin label (a 


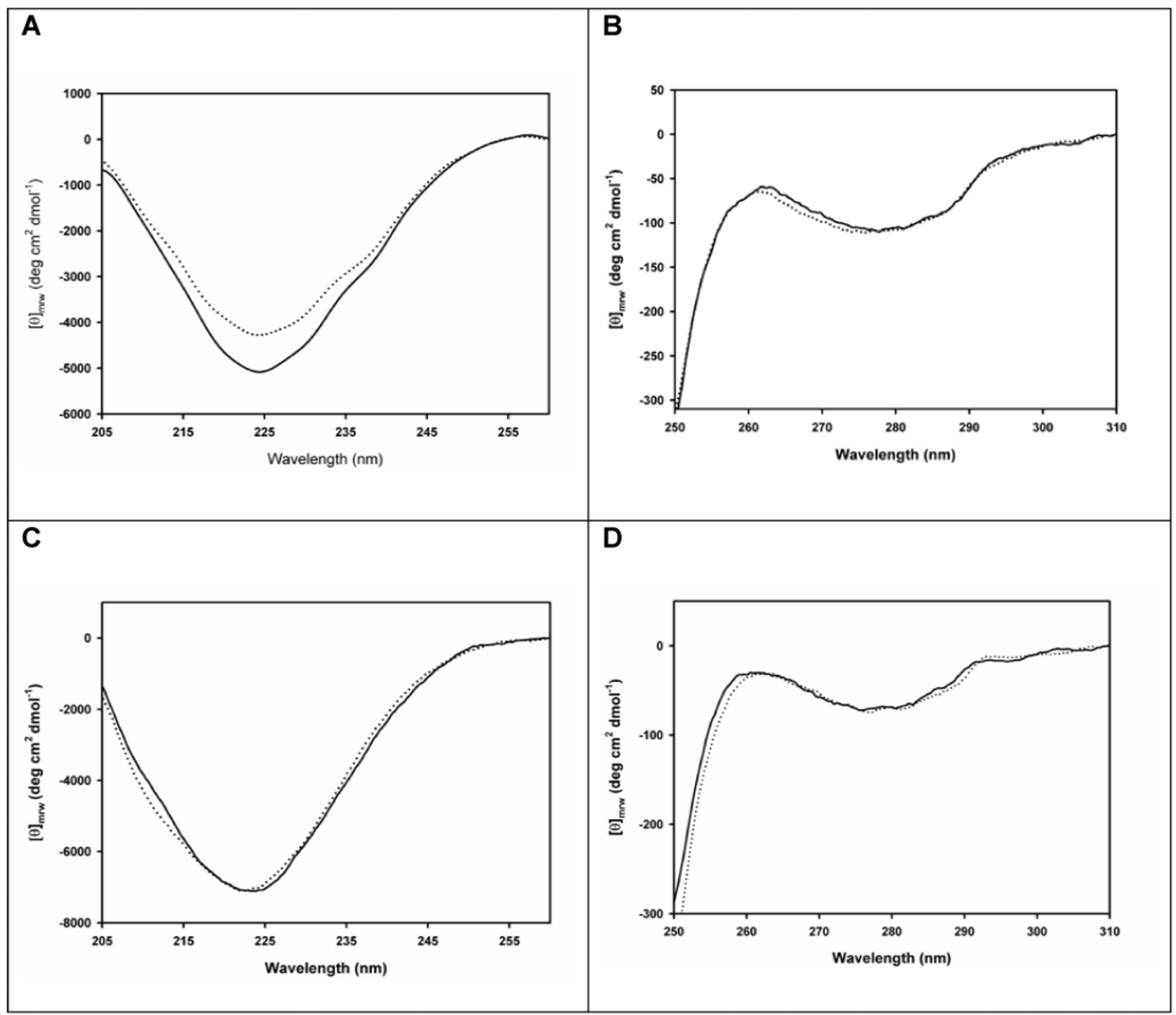

Figure 3

Far and near UV circular dichroism spectra of fresh and incubated lyophilized and co-lyophilized preparations of subtilisin C. CD spectra are shown for samples freshly suspended in I,4-dioxane (solid lines) and after further incubation for 4 days (dotted lines)(A) Far UV CD of lyophilized subtilisin C. (B) Near UV CD of lyophilized subtilisin C. (C) Far UV CD of subtilisin C. colyophilized with methyl- $\beta$-cyclodextrin. (D) Near UV CD of subtilisin C. co-lyophilized with methyl- $\beta$-cyclodextrin. 


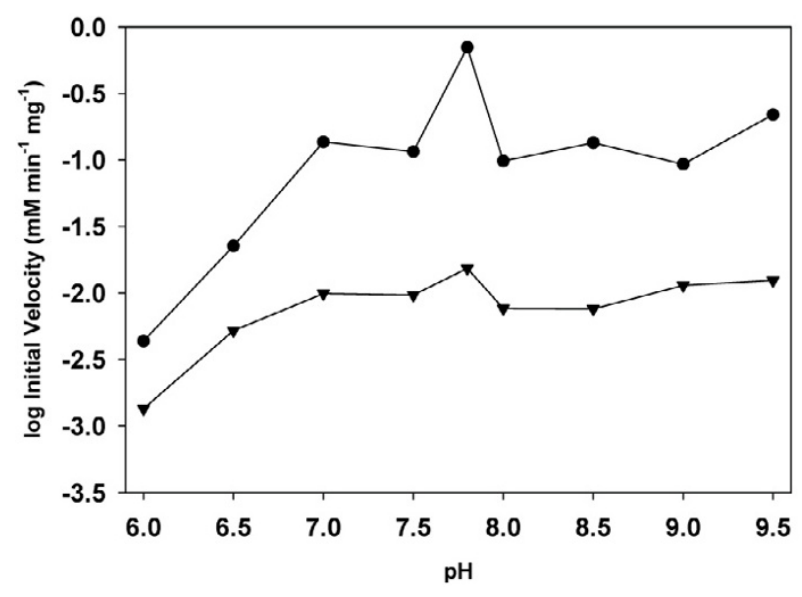

Figure 4

Effect of $\mathrm{pH}$ of co-lyophilized subtilisin $\mathrm{C}$. before and after storage in I,4-dioxane. Activity was measured for subtilisin C. co-lyophilized with methyl $\beta$ cyclodextrin, then freshly suspended in I,4-dioxane (O), and after incubation for 4 days $(\nabla)$.



\section{Figure 5}

Effect of $\mathrm{pH}$ of lyophilized subtilisin $\mathrm{C}$. before and after storage in I,4-dioxane. Activity was measured for lyophilized subtilisin C. freshly suspended in I,4-dioxane ( $\nabla)$, and after incubation for 4 days $(\mathbf{O})$.

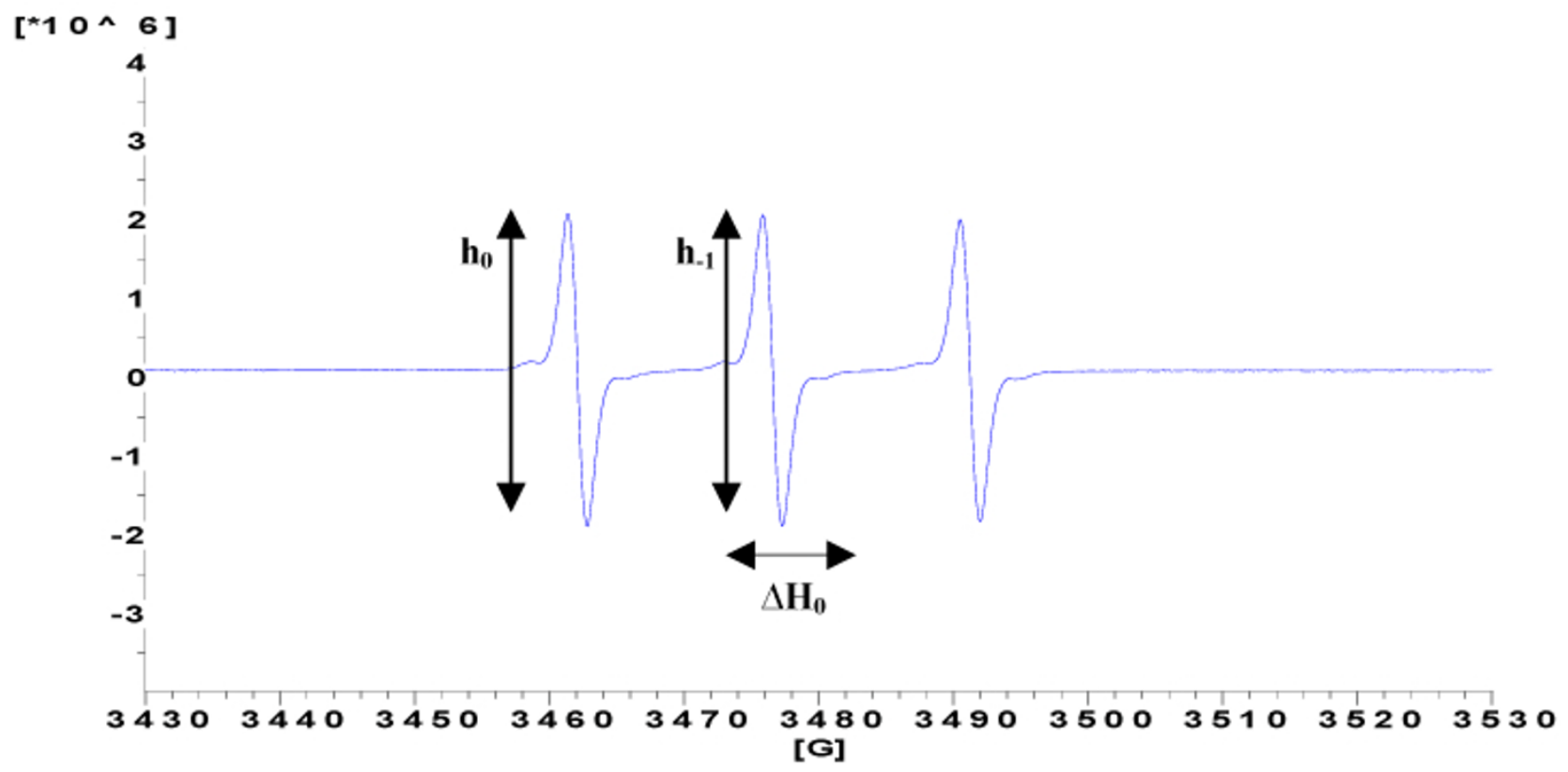

Figure 6

Characteristic EPR signal of the spin label in solution. 
high value of $\mathbf{h}_{\mathrm{i}} /\left(\mathbf{h}_{\mathrm{i}}+\mathbf{h}_{\mathrm{a}}\right)$ indicates higher degree of freedom). For our studies, lyophilized subtilisin Carlsberg was spin-labeled at the active site with a classic inhibitor for serine proteases: 4-ethoxyfluorophosphinyloxyTEMPO (Figure 8). After labeling, activity and active site titrations were performed to ensure the enzyme was in fact labeled at the active-site (Materials and Methods). Our results, summarized on (Figure 7 ), indicate that the degree of freedom (or mobility) of the spin label, bound to the enzyme's active site, increases during the five days of incubation. Although Tau could not be measured at day 0 (no incubation ), $\Delta \mathbf{H}_{0}$ and $\mathbf{h}_{\mathrm{i}} /\left(\mathbf{h}_{\mathrm{i}}+\mathbf{h}_{\mathrm{a}}\right)$ show that the mobility of the spin label increases after a 4-day incubation, suggesting increased flexibility of the enzyme or "over relaxation" of the active site. Besides the activity loss observed, increased mobility of the spin label seems to be the only consequence of incubation in 1,4-dioxane, and it could therefore be interpreted as the cause for the low enzyme stability. If, however, one argues that increased mobility of the spin-label relates to increased enzyme flexibility, then these results seem to be contradictory to the general belief that increasing the flexibility should increase the enzyme's activity, unless the enzyme's flexibility was already at its optimum before incubation, and increased flexibility would only cause a decrease in activity. But perhaps the most plausible explanation is that the enzyme's active-site is becoming distorted or "over relaxed" during incubation, and this results in a decrease in $\mathrm{V}_{\mathrm{max}} / \mathrm{K}_{\mathrm{M}}$, in initial activity and an increase in apparent flexibility of the spin label is observed. Since added water has been reported to increase an enzyme's flexibility $[25,26]$, changes of hydration water from the enzyme (occurring during the incubation period) could explain the increased flexibility observed after the 5-day incubation period. To determine this, we conducted a series of incubation and EPR measurements in 1,4-dioxane $+0.5 \%$ of added water and controlling its water activity using hydrated $\mathrm{BaBr}_{2}$ salts.

\section{EPR studies of subtilisin C. in I,4-dioxane with $0.5 \%$ water and controlling the water activity}

Spin-labeled lyophilized subtilisin C. was suspended in 1,4-dioxane, water $(0.5 \% \mathrm{v} / \mathrm{v})$ was added, and the EPR spectra were recorded at day 0 (no incubation) and day 4 of storage in this solvent. The results show that in the presence of water, at day zero (no incubation), the spin label has a higher degree of mobility than that of the enzyme suspended in the neat solvent $\left(\Delta \mathbf{H}_{0}\right.$ is smaller while $\mathbf{h}_{\mathbf{i}} /$ $\left(h_{i}+h_{a}\right)$ is larger - consistent with increased mobility of the spin label, (Figure 7)). Incubation of the hydrated enzyme for 5 days in this solvent shows only a moderate increase in the spin label mobility, as determined from the values of Tau, $\Delta \mathbf{H}_{0}$ and $\mathbf{h}_{\mathbf{i}} /\left(\mathbf{h}_{\mathbf{i}}+\mathbf{h}_{\mathbf{a}}\right)$. However, when these experiments were repeated controlling the water activity, no increase in enzyme flexibility was observed
(Figure 7). Since hydration has a clear effect on the enzyme flexibility, and it has been well documented that added water can alter the enzyme activity, we decided to look at the effect of hydration on enzyme storage stability further.

\section{Enzyme storage stability in the presence of $0.5 \%$ water and controlling the water activity}

To address the issue of changes of the enzyme's hydration level as a possible cause for the observed low solvent storage stability, we incubated the lyophilized and the colyophilized powders in 1,4-dioxane with $0.5 \%(\mathrm{v} / \mathrm{v})$ water added to the solvent and controlling the water activity using pre-hydrated $\mathrm{BaBr}_{2}$ salts directly added to the solvent. The results show that regardless of the water content, both preparations lose their initial high activity during incubation. The lyophilized powder is initially activated (with the addition of water), but its activity decreases rapidly after $24 \mathrm{~h}$, and a similar behaviour is observed when the water activity is controlled (Figure 9). However the activity of the colyophilized enzyme is diminished with the addition of water (as it has been previously reported) [25], and it decreases further with incubation (Figure 10). Controlling the water activity actually results in an initial increase in enzyme activity, but it also declines to approximately the same value after incubation (Figure 10). These results suggest (but do not exclude other mechanisms) that the low enzyme storage stability is not due to a hydration/dehydration effect. The fast enzyme inactivation observed when water is added should not be due to denaturation of the protein because its activity is preserved after the incubation period (the remaining activity is similar to that of the enzyme in neat solvent). This could be due to a general effect that is also observed with other enzyme formulations, such as colyophilized and pegylated, where the initial enzyme activity is high but the stability in the solvent is lower than the lyophilized powder $[14,15]$.

\section{Discussion}

It is clear that loss of activity is not due to any major change in structure. Other possible mechanisms include changes in the ionization state of critical residues in the enzyme, changes in the enzyme flexibility, or in the enzyme's hydration level which could also have an effect on its flexibility. Our stability data obtained with $0.5 \%$ water and with controlled water activity rules out hydration of the enzyme as the cause. Change in hydration is one factor that may affect both activity and flexibility without significant change in protein structure. Our experiments varying the water content of the organic solvent in which the enzyme is incubated are informative here. The quite different changes in flexibility seen with different water levels suggest that hydration is a major contributor to these effects. 


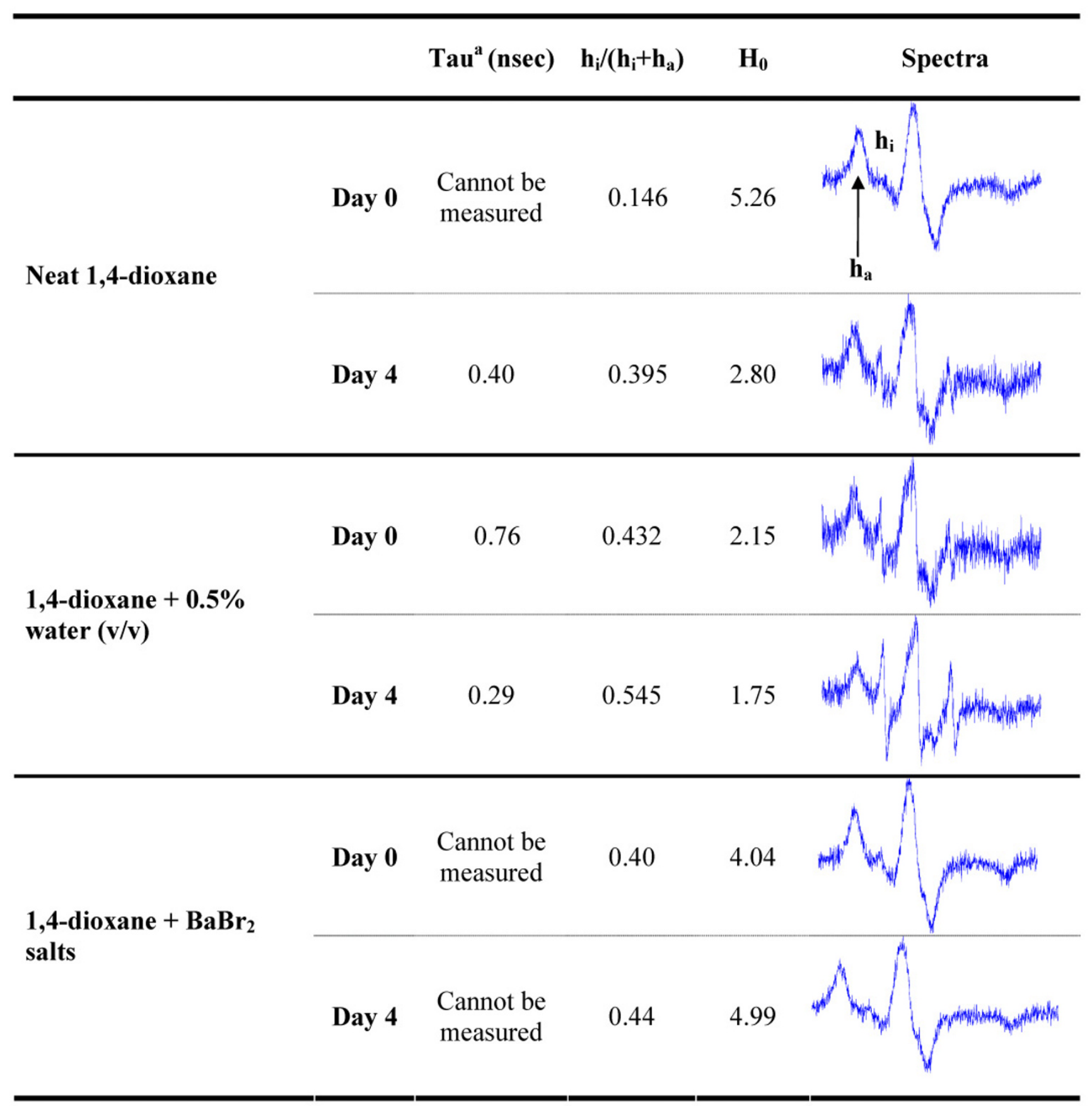

Figure 7

Effect of water $(0.5 \% \mathrm{v} / \mathrm{v})$ and controlled water activity during incubation of 4-EFPO-TEMPO-labeled Subtilisin Carlsberg in I,4-dioxane by EPR Spectroscopy. 


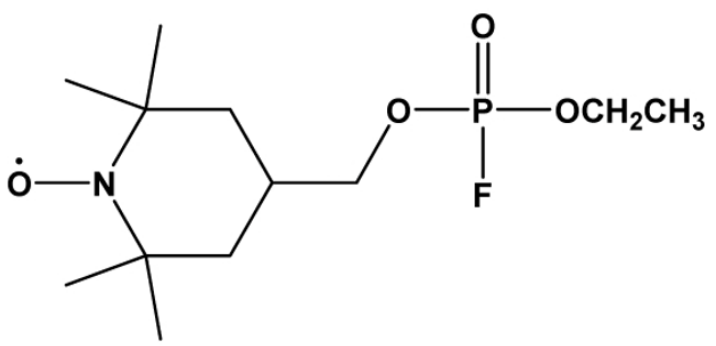

Figure 8

Structure of 4-Ethoxyfluorophosphinyloxy-TEMPO.

In contrast, the much smaller effects of water level on inactivation over time suggest that this process is not so closely related to hydration (or indeed to flexibility changes). However, we certainly cannot exclude processes involving protein-bound water molecules. Activity could be affected by the loss or movement of just one or two water molecules close to the active site. Such changes might even be opposite to those in the total amount of enzyme-bound water.

The $\mathrm{pH}$ memory experiments tend to exclude changes in the ionization state as the cause, but the increase in $\mathrm{K}_{\mathrm{M}}$ observed could be the result of small but critical changes in the structure around the active-site. It is also interesting to compare these findings with the inactivation of subtilisin Carlsberg, in silica immobilised or CLEC form, during continuous operation in acetonitrile based media [27]. In this case no activity can be recovered on returning the catalyst to aqueous media [27], and CD, infrared and fluores-

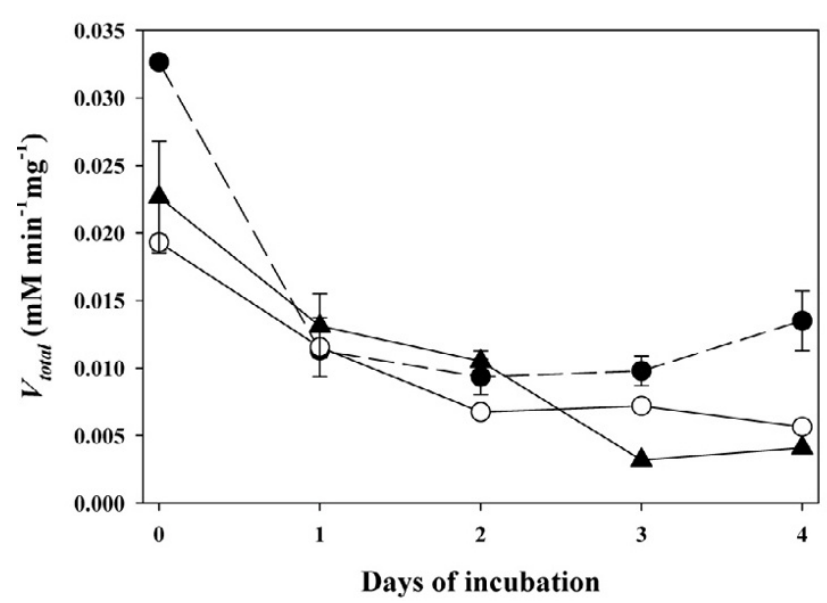

Figure 9

Storage stability of lyophilized subtilisin Carlsberg in I,4dioxane: $(\bigcirc)$ neat, $(\mathbf{O})$ with $0.5 \% \mathrm{H}_{2} \mathrm{O}$ added, and $(\mathbf{A})$ controlling water activity with $\mathrm{BaBr}_{2}$ salts. cence measurements reveal extensive structural changes (Ganesan et al (2006), and further unpublished work). Clearly the mechanisms involved here are quite different than the storage stability studied in the present paper, perhaps the immobilized enzyme used in that study is more susceptible to structural or flexibility changes than the "native" enzyme?

\section{Conclusion}

Our studies of secondary and tertiary structure show that the enzyme remains structurally defined during prolonged incubation in organic solvents. Changes in the enzyme hydration or aggregation do not seem to be responsible for the observed poor storage stability, although it is possible that in the presence of water, we could be observing two competing effects (activation and fast deactivation) which prevent us from clearly separating the two effects (low storage stability from a deactivation/activation effect of added water). The flexibility of the active-site spin label increases with increased water concentration, but it remains constant during the storage period when the water activity is controlled by added hydrated salts. The observed decrease in activity is also accompanied by an increase in $\mathrm{K}_{\mathrm{M}}$ and a decrease in $\mathrm{V}_{\max }$, showing loss of the catalytic efficiency of the enzyme.

These results exclude structural changes, flexibility, hydration, and changes of the enzyme ionization state as possible mechanism for the observed low storage stability, but do not exclude possible depletion or rearrangement of water molecules around the active site, or small structural perturbations around the active site or movements of

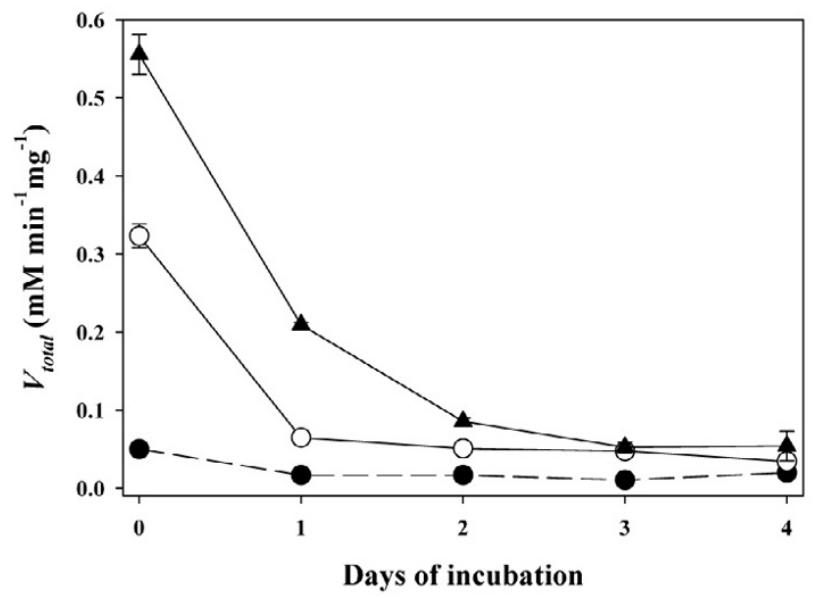

\section{Figure 10}

Storage stability of subtilisin Carlsberg co-lyophilized with methyl- $\beta$-cyclodextrin in I,4-dioxane: $(\bigcirc)$ neat, $(0)$ with $0.5 \% \mathrm{H}_{2} \mathrm{O}$ added, and $(\boldsymbol{\Delta})$ controlling water activity with $\mathrm{BaBr}_{2}$ salts. 
counter ions. Further comprehensive studies will be required to ascertain this.

\section{Methods}

\section{Enzymes and reagents}

Subtilisin Carlsberg (alkaline protease from Bacillus licheniformis, EC 3.4.21.14) and sec-phenethyl alcohol were purchased from Sigma/Aldrich (St. Louis, MO). The solvents were purchased from Aldrich in the anhydrous form (Sure/Seal bottles, water content below 0.005\%). Vinyl butyrate was purchased from TCI America (Portland, OR). The spin label 4-ethoxyfluorophosphinyloxyTEMPO (4-EFPO-TEMPO) was purchased from Toronto Research Chemicals (North York, Canada).

\section{Enzyme preparation and kinetic measurements}

Subtilisin C. powder was prepared by $24 \mathrm{~h}$ lyophilization from a solution of $5 \mathrm{mg} / \mathrm{mL}$ in a $20 \mathrm{mM}$ potassium phosphate buffer at $\mathrm{pH}$ 7.8. Colyophilization with $M \beta C D$ was done by lyophilizing the enzyme from a buffer solution containing the additive at a 1:6 weight ratio of enzyme to additive. The model transesterification reaction between sec-phenethyl alcohol and vinyl butyrate was followed by gas chromatography. The GC instruments (HP 6850 and HP 6890, fitted with Chirasil CB columns, FID detectors and He as carrier gas) were calibrated with the chiral ester products of the reactions. The product peak areas and retention times were the same in the presence or absence of the substrates. The substrates $(70 \mathrm{mM}$ alcohol and 200 $\mathrm{mM}$ vinyl butyrate) and the solvent $(1.0 \mathrm{~mL})$ were stored over activated $3 \AA$ molecular sieves prior to their use. All kinetic experiments were terminated before $10 \%$ of the product was formed. The enzyme enantioselectivity was determined by measuring the initial rates of enantiomeric product formation [28]. The retention times of the " $R$ " and "S" products were obtained using samples of the pure enantiomers synthesized from the corresponding alcohol enantiomers. The enzyme enantioselectivity is equal to the ratio: $\left[\mathrm{k}_{\mathrm{cat}} / \mathrm{K}_{\mathrm{M}}\right]_{\mathrm{R}} /\left[\mathrm{k}_{\mathrm{cat}} / \mathrm{K}_{\mathrm{M}}\right]_{\mathrm{S}}=\mathrm{V}_{\mathrm{R}}[\mathrm{S}] / \mathrm{V}_{\mathrm{S}}[\mathrm{R}]$ [29].

\section{Enzyme hydration and controlled activity experiments}

Water activity was controlled using hydrated salt pairs as described [30]. The mixture of $\mathrm{BaBr}_{2} \bullet 1 \mathrm{H}_{2} \mathrm{O} / \mathrm{BaBr}_{2}$ was prepared by placing the anhydrous salt $(5 \mathrm{~g} / 16.8 \mathrm{mmol})$ over pure water $(75.8 \mathrm{mg} / 4.2 \mathrm{mmol})$ in a sealed vessel saturated with water vapor [30]. The enzyme activity measurements performed at the resulting water activity of 0.008 were carried out as described above with the following modifications: The mixture of $\mathrm{BaBr}_{2} \bullet 1 \mathrm{H}_{2} \mathrm{O} / \mathrm{BaBr}_{2}$ $(100 \mathrm{mg})$ was added to the solvent $(1 \mathrm{~mL})$ containing the enzyme and vinyl butyrate. The suspension was equilibrated by shaking at $45^{\circ} \mathrm{C}$ and $300 \mathrm{rpm}$ for $60 \mathrm{~min}$. Then, the alcohol was added and the reaction monitored as described above.

\section{Enzyme stability in organic solvents}

Enzyme stability was determined by measuring the enzyme activity (initial velocity) as a function of the incubation time (for up to 4 days) as follows: vials containing the enzyme (lyophilized powder: $10 \mathrm{mg}$, and co-lyophilized: $1.0 \mathrm{mg}$ ) suspended in $1.0 \mathrm{~mL} \mathrm{1,4-dioxane} \mathrm{under} \mathrm{N}_{2}$, were incubated at $45^{\circ} \mathrm{C}$ under constant shaking (300 $\mathrm{rpm}$ ). To measure the enzyme activity at different incubation times, the substrates were added to initiate the reaction and the kinetics followed as previously described.

Michaelis constants $\left(K_{M}\right), V_{\text {max }}$ and enzyme concentration The apparent Michaelis constants and $\mathrm{V}_{\max }$ were determined by plotting $\mathrm{V}_{\mathrm{s}} \mathrm{vs} \mathrm{V}_{\mathrm{s}} /[\mathrm{S}]$ measured for the model transesterification reaction between phenyl alcohol and vinyl butyrate. The alcohol concentration was increased from 1 to $100 \mathrm{mM}$, while the activated ester concentration was kept constant at $200 \mathrm{mM}$. The active enzyme concentration was determined following a published procedure [18].

\section{pH profile experiments}

The enzyme was lyophilized and co-lyophilized from 20 $\mathrm{mM}$ potassium phosphate buffers of varying $\mathrm{pH}$, adjusted as needed with dilute solutions of $\mathrm{NaOH}$ or $\mathrm{HCl}$. The initial activities (for the transesterification reaction between sec-phenethyl alcohol and vinyl butyrate) at day 0 and after a 7-day incubation period were measured for each of the enzymes (prepared from buffers of different $\mathrm{pH}$ ).

\section{FTIR experiments}

FTIR studies were conducted with a Nicolet Magna-IR System 560 optical bench as described $[20,28,31,32]$. A total of 256 scans at $2 \mathrm{~cm}^{-1}$ resolution using Happ-Ganzel apodization were averaged to obtain each spectrum. Aqueous spectra were measured using spacers of $<15 \mu \mathrm{m}$ thickness. Lyophilized protein powders (lyophilized and colyophilized) were measured as $\mathrm{KBr}$ pellets (1 $\mathrm{mg}$ of protein per $200 \mathrm{mg}$ of $\mathrm{KBr}$ ). Pellets were produced using a Spectra Tech Macro-Micro KBr Die Kit and Carver 12-ton hydraulic press. Enzyme powders in organic solvents were prepared by sonication for $2 \mathrm{~min}$ in a sonication bath and measured in a FTIR cell equipped with $\mathrm{CaF}_{2}$ windows and using $100 \mu \mathrm{m}$ thick spacer. When necessary, spectra were corrected for the solvent background and water vapor contributions in an interactive manner using the Nicolet OMNIC 3.1 software to obtain the protein's vibration spectra. Each protein sample was measured at least five times [20,32].

\section{Second derivatization}

All spectra were analyzed by second derivatization in the amide I region (1700-1600 $\left.\mathrm{cm}^{-1}\right)$. The second derivative spectra were obtained with the derivative function of Omnic 3.1 software (Nicolet). The final protein spectrum 
were smoothed with an 11-point smoothing function $\left(10.6 \mathrm{~cm}^{-1}\right)$. Amide I second derivative spectra were also used to calculate the spectral correlation coefficient (see below).

\section{Calculation of the correlation coefficient}

Spectral correlation coefficient values (SCC) to quantify procedure-induced protein structural perturbations were calculated as described using the amide I second derivative spectra $[19,28]$. After correcting the spectra for the background and all water vapor contributions, the second-derivative spectra in the amide I spectral region were calculated and smoothed twice with a $10.6 \mathrm{~cm}^{-1}$ function. Next, these second-derivative spectra were saved for the spectral range from $1700-1600 \mathrm{~cm}^{-1}$ on identical wavenumber scales and with identical data spacing. The data for the reference spectrum (e.g. the native in aqueous medium) and the spectrum with the varied condition (e.g. after suspension in organic solvent) were imported into the program Sigma Plot and the correlation coefficient was calculated as described in detail by Griebenow et al [28]. An SCC of 1.0 indicates that two spectra being compared are the same.

\section{Circular Dichroism experiments}

Far and near UV Circular Dichroism spectra (CD) of lyophilized and co-lyophilized subtilisin C. were studied in 1,4-dioxane, before and after incubation for 4 days as described. CD spectra were measured at room temperature in a Jasco 810 spectropolarimeter fitted with a rotating sample cell holder. Full details are described in Ganesan et al (2006). Far UV CD and near UV CD spectra were measured using cells of path length $0.01 \mathrm{~cm}$ and 0.5 $\mathrm{cm}$, respectively. The spectra were an average of 5 scans collected at a scan speed of $50 \mathrm{~nm} / \mathrm{min}$ and bandwidth 1 $\mathrm{nm}$ for far UV and $1.5 \mathrm{~nm}$ for near UV. After the measurement was completed the content of the sample cell was collected (with rinsing), air dried and dissolved in deionized water and protein concentration was estimated from UV absorption at $280 \mathrm{~nm}$.

\section{Preparation of spin labeled subtilisin}

Subtilisin Carlsberg was spin labeled at the active site Ser221 with 4-ethoxyfluorophosphinyloxy-TEMPO (Figure 8 ) by the method of Morrisett and Broomfield with minor modifications in the published protocol [33]. After the reaction, the remaining free radical was removed using Sephadex G25 desalting columns (Amersham Biosciences). The spin labeled enzyme free of any unbound spin label was thereafter lyophilized and used for the EPR analysis. Active site titration using a published protocol [34] revealed a $100 \%$ reduction on the number of enzyme-active-sites (accompanied also by loss of enzyme activity), demonstrating that indeed, spin-labeling took place at the active-site. Organic solvents dried overnight over molecular sieves were used for the EPR analysis. The incubation of labeled enzyme in organic solvents was carried out at room temperature. All EPR spectra were recorded at room temperature on a Bruker EMX EPR spectrometer with a microwave power of $2.0 \mathrm{~mW}$, a microwave frequency of $9.7 \mathrm{GHz}$ and a sweep width of $100 \mathrm{G}$ (resolution 1024 points). Every spectrum was obtained from multiple scans.

\section{Authors' contributions}

$\mathrm{BC}$ carried out the FTIR and incubation studies, and helped draft the manuscript. VB carried out the EPR studies. AG completed the CD studies. PH helped designing the study and drafting the manuscript. FS carried out some of the preliminary FTIR experiments and helped draft the manuscript. AF completed the $\mathrm{pH}$ profile and the active site titration study. KG and GB conceived the study, participated in its design and coordination, and drafted the manuscript. All authors read and approved the final manuscript.

\section{Acknowledgements}

We thank EPSRC and BBSRC (UK) for support of the CD studies. Contract grant sponsor: National Institute of Health, grant numbers: S06 GM-08216, S06 GM08102, P20 RRI6439, and by NIH Grant Number P20 RR-016470 from the INBRE Program of the National Center For Research Resources.

\section{References}

I. Effenberger F, Syed J: Stereoselective synthesis of biologically active tetronic acids. Tetrahedron 1998, 9:8|7-825.

2. Jungen $M$, Gais $H$ : Application of pig liver esterase catalyzed transesterification in organic media to the kinetic resolution of glycerol derivatives. Tetrahedron Asymmetry 1999, I0:3747-3758.

3. Klibanov AM: Improving enzymes by using them in organic solvents. Nature 200I, 409:24I-246.

4. Lee T, Jones JB: Probing the abilities of synthetically useful serine proteases to discriminate between the configurations of remote stereocenters using chiral aldehyde inhibitors. J Am ChemSoc 1996, I I 8:502-508.

5. Macritchie JA, Silcock A, Willis CL: Enantioselective synthesis of unsaturated $\alpha$-hydroxy acids. Tetrahedron: Asymmetry 1997, 8:3895-3902.

6. Roberts SM, Williamson NM: The use of enzymes for the preparation of biologically active natural products and analogues in optically active form. Curr Org Chem 1997, I:I-20.

7. Sanchez VM, Rebolledo F, Gotor V: Candida antarctica lipasecatalyzed doubly enantioselective aminolysis reactions. Chemoenzymatic synthesis of 3-hydroxypyrrolidines and 4(silyloxy)-2-oxopyrrolidines with two stereogenic centers. J Org Chem 1999, 64: I 464-I470.

8. Zaks A, Klibanov AM: Enzymatic catalysis in nonaqueous solvents. J Bio Chem 1988, 263:3194-320I.

9. Carrea G, Riva S: Properties and Synthetic Applications of Enzymes in Organic Solvents. Angew Chem lnt 2000, 39:2226-2254.

10. DeSantis G, Davis BG: The expanding roles of biocatalysis and biotransformation. Curr Opin Chem Biol 2006, 10:139-140.

II. Fitzpatrick PA, Steinmetz ACU, Ringe D, Klibanov AM: Enzyme crystal structure in a neat organic solvent. Proc Natl AcadSci USA 1993, 90:8653-8657.

12. Griebenow K, Klibanov AM: Lyophilization-induced reversible changes in the secondary structure of proteins. Proc Natl Acad Sci USA 1995, 92:10969-10976.

13. Fagain CO: Enzyme stabilization-recent experimental progress. Enzyme and Microbial Technology 2003, 33:137-I 49. 
14. Gonzalez S, Martinez EA, Cordero L, Ferrer A, Montanez I, Barletta G: High Initial Activity but Low Storage Stability Observed for Several Preparations of Subtilisin Carslberg Suspended in Organic Solvents. Biotechnol Prog 2002, I8: |462-I 466.

15. Castillo B, Pacheco Y, Al-Azzam W, Griebenow K, Devi M, Ferrer A, Barletta G: On the activity loss of hydrolases in organic solvents: I. Rapid loss of activity of a variety of enzymes and formulations in a range of organic solvents. Journal of Molecular Catalysis B: Enzymatic 2005, 35: 147-I53.

16. Yennawar NH, Yennawar HP, Farber GK: X-ray crystal structure of $\gamma$-chymotrypsin in hexane. Biochemistry 1994, 33:7326-7336.

17. Fernandez JFA, Halling P: Operational Stability of High Initial Activity Protease Catalysts in Organic Solvents. BiotechnolProg 2002, I 8: | $455-1457$.

18. Wangikar PP, Carmichael D, Clark D, Dordick JS: Active-site titration of serine proteases in organic solvents. Biotechnol Bioeng 1996, 50:329-335.

19. Prestrelski SJ, Arakawa T, Carpenter JF: Separation of freezingand drying-induced denaturation of lyophilized proteins using stress-specific stabilization. Arch Biochem Biophys 1993 303:465-473.

20. Griebenow K, Klibanov AM: On protein denaturation in aqueous-organic mixtures but not in pure organic solvents. J Am Chem Soc 1996, II 8: I 195-11700

21. Desai UR, Klibanov AM: Assessing the structural integrity of a lyophilized protein in organic solvents. J Am Chem Soc 1995 I I 7:3940-3945.

22. Hubbell WL, Cafiso DS, Altenbach C: Identifying conformational changes with site-directed spin labeling. Nature StructuralBiology 2000, 7:735-739.

23. Hamilton CL, McConney : Structural chemistry and molecular biology. WH Freeman and Company 1968.

24. Steinhoff $H J$ : Methods for study of protein dynamics and protein-protein interaction in protein-ubiquination by electron paramagnetic resonance spectroscopy. Frontiers in Bioscience 2002, 7:97-II0.

25. Santos AM, Montañez I, Barletta G, Griebenow K: Activation of serine protease subtilisin Carlsberg in organic solvents: combined effect of methyl- $\beta$-cyclodextrin and water. Biotechnol Lett 1999, 21: III3-1 II8.

26. Halling PJ: What can we learn by studying enzymes in nonaqueous media? Philosophical Transactions of the Royal Society of London Series B-Biological Sciences 2004, 359: I287-I 297.

27. Ganesan A, Kelly SM, Petry I, Moore BD, Halling PJ: Circular dichroism studies of subtilisin Carlsberg immobilised on micron sized silica particles. Biochim Biophys Acta 2006, I 764: I I I9-I I 25.

28. Griebenow K, Laureano Y, Santos AM, Montanez I, Rodriguez L, Vidal MW, Barletta G: Improved enzyme activity and enantioselectivity in organic solvents by methyl- $\beta$-cyclodextrin. J Am Chem Soc 1999, 121:8157-8163.

29. Fersht A: Enzyme Structure and Mechanism. 2nd edition. Freeman and Company; 1985.

30. Schmitke JL, Wescott CR, Klibanov AM: The mechanistic dissection of the plunge in enzymatic activity upon transition from water to anhydrous solvents. J Am Chem Soc 1996, I I 8:3360-3365.

3I. Carrasquillo K, Sanchez K, Griebenow K: Relationship between conformational stability and lyophilization-induced structural changes in chymotrypsin. Biotechnol Appl Biochem 2000, 3I:4I-53.

32. Griebenow K, Klibanov AM: Can conformational changes be responsible for solvent and excipient effects on the catalytic behavior of subtilisin Carlsberg in organic solvents? Biotechnol Bioeng 1997, 53:35I-362.

33. Morrisett JD, Broomfield CA: A comparative study of spinlabeled serine enzymes: acetylcholinesterase, trypsin, $\alpha$-chymotrypsin, elastase, and subtilisin. The Journal of Biological Chemistry |97|, 247:7224-723|.

34. Schonbaum GR, Zerner B, Bender ML: The spectrophotometric determination of the operational normality of an alpha-chymotrypsin solution. J Biol Chem 1961, 236:2930-2935.
Publish with Bio Med Central and every scientist can read your work free of charge

"BioMed Central will be the most significant development for disseminating the results of biomedical research in our lifetime. "

Sir Paul Nurse, Cancer Research UK

Your research papers will be:

- available free of charge to the entire biomedical community

- peer reviewed and published immediately upon acceptance

- cited in PubMed and archived on PubMed Central

- yours - you keep the copyright
BioMedcentral 